\title{
Executive Function Performance Test: transcultural adaptation, evaluation of psychometric properties in Brazil
}

\author{
Teste de Desempenho da Função Executiva: adaptação transcultural, avaliação das \\ propriedades psicométricas no Brasil
}

Juliana Conti', Sonia Maria Dozzi Brucki ${ }^{1}$

\begin{abstract}
Executive dysfunction occurs in $18.5 \%$ to $39 \%$ of patients who present with cognitive impairment. Occupational therapy aims to facilitate independence and autonomy, hence improving quality of life. The Executive Function Performance Test - Brazilian version (EFPT-BR) has been developed to assess the need for assistance in performing four basic daily tasks. Objectives: The aims of this research were: (1) to offer cross-cultural adaptation in patients with stroke; (2) to assess the psychometric properties of the Brazilian version of the EFPT-BR in patients with stroke; (3) to assess the relationship between scores on the EFPT-BR in patients with stroke, and demographic variables, stroke location, symptoms of anxiety and depression. Methods: The transcultural adaptation and validation were performed based on standard procedures, and psychometric properties were assessed in 86 Brazilian patients who suffered a stroke. Results: The test has shown a good internal consistency (Cronbach's alpha: 0.819). The ICC for intra-rater reliability was 0.435 and for the inter-rater was 0.732 . Significant correlations between scores in the EFPT-BR and executive measures (verbal fluency test, clock drawing test, digit span forwards and backwards, zoo map test and Six Elements Test) were observed. Conclusion: The EFPT-BR is a valid and reliable tool for occupational therapists to assess executive dysfunction in daily routine tasks in patients with stroke in Brazil.
\end{abstract}

Keywords: stroke; executive function; occupational therapy; cognition; validation studies.

\section{RESUMO}

Disfunção executiva ocorre em 18,5\% a 39\% dos pacientes que apresentam comprometimento cognitivo. A terapia ocupacional visa proporcionar independência e autonomia, de modo a melhorar a qualidade de vida. O Teste Desempenho da Função Executiva (TDFE) foi desenvolvido para avaliar a necessidade de assistência para realizar quatro tarefas diárias básicas. Objetivos: Os objetivos desta pesquisa são: (1) realizar a adaptação transcultural em pacientes com AVC; (2) avaliar as propriedades psicométricas da TDFE em pacientes com AVC; (3) avaliar a relação entre TDFE em pacientes com AVC e variáveis demográficas, região afetada pelo acidente vascular cerebral, sintomas de ansiedade e depressão. Métodos: A adaptação e validação transcultural foram realizadas com base em procedimentos padrão e as propriedades psicométricas foram avaliadas em 86 pacientes brasileiros que sofreram acidente vascular cerebral. Resultados: 0 teste apresentou boa consistência interna (alfa de Cronbach: 0,819). A confiabilidade intra examinador foi de 0,435 e para o inter examinador foi de 0,855. Foram observadas correlações significativas entre a pontuação final do TDFE e os seguintes testes de função executiva: teste de fluência verbal, teste do desenho do relógio, Teste de Extensão dos Dígitos (diretos e inversos), subteste do mapa zoológico e subteste modificado dos seis elementos. Conclusão: A TDFE é uma ferramenta válida e confiável para os terapeutas ocupacionais para avaliar a disfunção executiva nas tarefas de rotina diária em pacientes com AVC no Brasil.

Palavras-chave: acidente vascular cerebral; função executiva; terapia ocupacional; cognição; estudos de validação.

According to the World Health Organization, stroke is defined as follows: "A stroke is caused by the interruption of the blood supply to the brain, usually because a blood vessel bursts

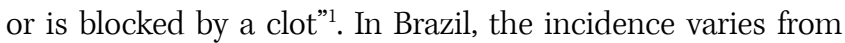
$105.4 / 100,000$ to $108 / 100,000$ per year $^{2,3}$. The incidence of stroke in young adults has increased, especially ischemic stroke ${ }^{4}$.
A stroke may lead to different disabilities, including cognition. Cognitive impairment after a stroke occurs in $30 \%$ to $55 \%$ of patients ${ }^{5,6,7}$ and contributes to decreased functional status ${ }^{7}$. In Brazil, in a 12-month study, $16.8 \%$ of patients presented with cognitive impairment $(12.2 \%$ with dementia $)^{8}$. 
Executive function is a cognitive function that controls the abilities related to new and complex tasks often seen in unusual situations that are novel or generate conflict in the person 9 . Consequently, individuals with executive dysfunction will have difficulties in performing their daily activities. Executive dysfunction frequently occurs after stroke, varying from $18.5 \%$ to $39 \%$ of patients. Some researchers have shown higher prevalences. These rates depend on methods used to assess these functions ${ }^{5,7}$. In patients with subcortical disease, dysexecutive syndrome is prominent in all patient groups, presenting as difficulties in tasks of planning, mental control, abstraction, perseveration, inhibitory control and processing speed, albeit to different degrees, depending on the degree of severity, from no cognitive impairment to cognitive impairment, and from no dementia to vascular dementia ${ }^{10}$.

Patients with a stroke, especially when they present with executive dysfunctions, show a worse performance in daily activities compared with healthy individuals ${ }^{11,12,13,14,15}$. Independence and autonomy in daily activities are important goals for the occupational therapist (OT) during the rehabilitation treatment ${ }^{16}$. Therefore, it is essential that the OT is able to assess all cognitive functions, including the executive functions.

The Executive Function Performance Test (EFPT) was developed by the Occupational Therapy Program of the Washington School University of Medicine in St. Louis, United States ${ }^{12}$. This instrument assesses the individual's need for assistance when performing simple daily tasks ${ }^{12}$. The instrument has been validated in Swedish ${ }^{17}$ and Korean ${ }^{18}$ for patients with stroke, in Hebrew for people with schizophrenia ${ }^{19}$, and in English for people with traumatic brain injury ${ }^{20}$.

The aims of this research were: (1) to offer cross-cultural adaptation, in Brazilian Portuguese, of the EFPT for patients with stroke; (2) to assess the psychometric properties of the Brazilian version of the EFPT-BR in patients with stroke; (3) to compare the scores in the EFPT-BR in patients with stroke with the demographic variables, stroke location, symptoms of anxiety and depression.

\section{METHODS}

\section{Population}

Eighty-six participants were assessed at least six months after stroke onset. All the participants were selected from the Hospital das Clínicas of the Universidade de São Paulo, in Brazil. The project was approved by the local ethics committee. All the participants were informed of the research objectives and informed consent was duly signed.

The inclusion criteria were: 1) age ranging from 18 to 80 years; 2) ischemic or hemorrhagic stroke. The patients were in the chronic stage, having had the lesion for at least six months, according to an MRI or CT scan; 3) able to collaborate with the evaluations (patients able to understand and complete all the test instruments and able to attend the appointments at the hospital for the evaluations). The exclusion criteria were: 1 ) severe depression, according to the DSM-IV and Hamilton Rating Scale for Depression; 2) other psychiatric disorders, such as alcoholism and schizophrenia; 3) clinical instability, such as tumor and chronic kidney disease; 4) other neurological diseases, such as dementia and Parkinson's disease; 5) patients using tricyclic antidepressants; and 6) receptive aphasia (difficulty understanding the instruments) assessed by informal evaluation of the aphasia .

The sample was classified using the Modified Rankin Scale ${ }^{21}$; the National Institutes of Health Stroke Scale (NIHSS) ${ }^{22}$; and the Edinburgh Inventory ${ }^{23}$ to assess handedness.

\section{Sample evaluation}

The functional evaluation comprised the Barthel Index ${ }^{24}$; Functional Activities Questionnaire (FAQ) ${ }^{25}$ : and the Lawton and Brody Instrumental Activities of Daily Living $(\mathrm{IADL})^{26}$ scale. The Stroke Impact Scale 3.0 $0^{27}$ assessed quality of life. Cognition was assessed by the Mini-Mental State Examination $^{28,29}$, and by the Brief Cognitive Screening Battery $^{30}$, which assesses naming, learning, delayed recall and recognition of drawings of 10 simple objects, verbal fluency (animals), and the clock drawing test.

Some specific tests involved executive functions: the Digit Span (backwards and forwards) ${ }^{31,32}$; the Stroop Color-Word Test for illiterates ${ }^{33}$; and the Zoo Map from the Behavioural Assessment of the Dysexecutive Syndrome ${ }^{34}$. All these instruments were selected as this was the first research study in this kind of population and we believed that a more comprehensive evaluation was preferable.

Patients were also assessed for depression and anxiety symptoms using two instruments: the Hospital Anxiety and Depression Scale ${ }^{35}$ and the Hamilton Depression Rating Scale ${ }^{36}$.

\section{Transcultural adaptation}

Transcultural adaptation and validation was developed according to the standards established by Guillemin and colleagues ${ }^{37,38}$, as shown in the Figure. The author ${ }^{12}$ had authorized us to translate and validate the EFPT-BR.

\section{Executive Function Performance Test - Brazilian version:}

The EFPT-BR assesses the amount of assistance that the participant requires to perform the following tasks: prepare a meal, make a phone call, take medication and pay utility bills ${ }^{12}$. The patient performs the task and the OT observes and, if necessary, offers supervision or assistance. The executive functions assessed in this test are initiation, 


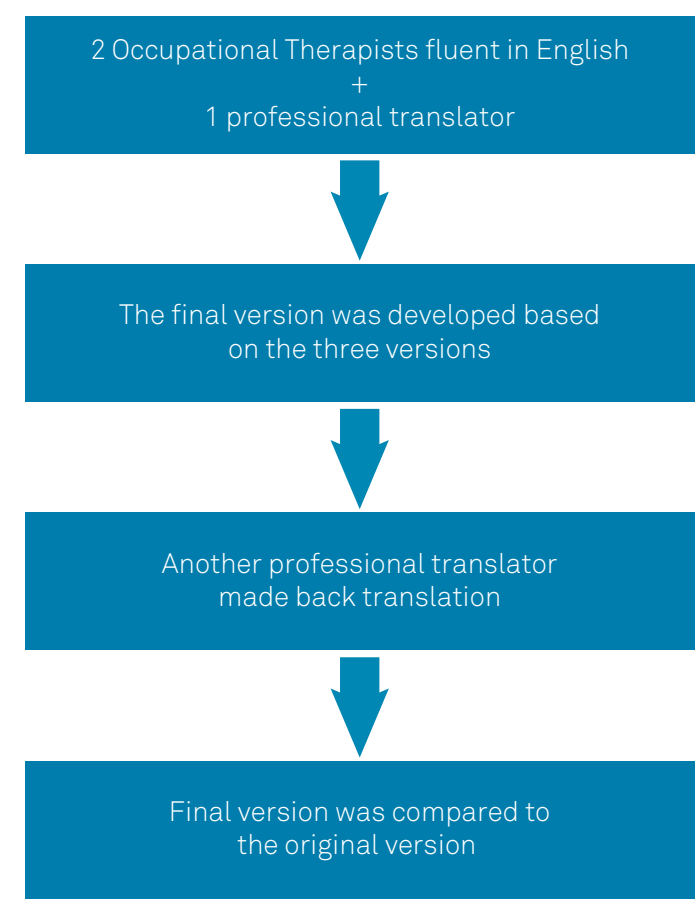

Figure. Transcultural adaptation.

organization, sequence, safety and judgment, and conclusion. The participant's performance is assessed according to five levels of assistance: (0): no assistance; (1) indirect verbal instruction; (2) gestural instruction; (3) direct verbal instruction; (4) physical assistance and (5) not able to complete part of the task or the whole task. The tasks comprise five items and the score is between 0-25 for each one. The higher the score, the worse the performance ${ }^{12}$. The authors agreed on the adaptation and use of the scale.

\section{Brazilian adaptation}

The Brazilian version required the following adaptations to be more suitable for the population: (1) simple meal preparation: oatmeal was substituted with making coffee; (2) a phone call to the supermarket was replaced by a phone call to a pharmacy; (3) taking medication: in Brazil, the patient's name is not usually on the medication bottle label. Therefore, the patient had to compare the name of the medication with the medical prescription and illiterate participants were asked to indicate the correct bottle according to color; (4) paying the bills: in Brazil, utility bills are not usually paid with a check. Utility bills are usually paid at a bank. For this task, the participant had to check the bank statement and separate the correct amount of money (play money) to pay the utility bill correctly.

\section{Psychometric properties}

The following psychometric properties of the Brazilian version of the EFPT-BR were assessed: 1 ) internal consistency; 2) inter- and intra-rater reliability; and 3) construct validity.

\section{Inter-and intra-rater reliability}

The intra-rater reliability was evaluated in 30 of the 86 participants, with an interval of 41.9 days between the two evaluations. The performance of 40 of the participants (40/86) was filmed for the second OT to evaluate and score, for inter-rater reliability.

\section{RESULTS}

The characteristics of the study sample are shown in Table 1: there was a predominance of men, right-handers and individuals with lesions in the left cerebral hemisphere. The mean time from stroke onset was 36 months (6-227) (median: $43.2 \pm 36.4$ ). The mean level of education was $7.4 \pm$ 5.0 years. The performances of the participants on the executive function scales are described in Table 2.

In general, the participants were independent in their daily routine, with a stable clinical condition and mild sequelae, as seen on the NIHSS (median $=1: 0-6$, mild neurological impairment) and the Barthel Index (median $=100$ : 40-100, independent for activities of daily living). In the American version ${ }^{12}$, the participants had an NIHSS of 2 (total mean score) for the mild stroke group; and 10.64 (total mean score) for the moderate stroke group.

\section{Executive Function Performance Test - Brazilian version}

The performance of the participants in the EFPT-BR is also shown in Table 2. The simple meal preparation and phone call had the best scores.

\section{Psychometric properties}

According to the result of Cronbach's alpha $=0.819$, the internal consistency of the EFPT-BR is considered to be good. Table 3 describes the results of the internal consistency for each task.

\section{Reliability}

The reliability of the EFPT-BR is shown in Table 4. Even though the results of the intra-rater reliability were not good, especially for the simple meal preparation and the phone call tasks, the results for the inter-rater reliability was good.

\section{Construct validity}

In Table 5, the total score of the EFPT-BR shows significant correlation with the following executive function instruments: Animal Verbal Fluency, Clock Drawing Test, Digit Span Test Forward and Backward, Zoo Map 1 and 2, Modified Six Elements, Barthel Index, FAQ and IADL scale. Paying a bill was the only task that showed a significant correlation with the executive function tests, with the exception of the Stroop test. When compared with the instrumental daily activities instruments, only the medication task showed a relevant correlation with these instruments. 
Table 1. Characteristics of the sample.

\begin{tabular}{|c|c|}
\hline Characteristics & $\mathrm{n}=86$ \\
\hline Age (mean \pm SD) & $62.7 \pm 10.9$ \\
\hline Gender (F/M) & $35 / 51$ \\
\hline Educational level (years) & $7.4 \pm 4.93$ \\
\hline Ethnic group (White/Black/Asian) & $66 / 17 / 3$ \\
\hline \multirow{5}{*}{ Lesion location } & Right hemisphere - 23 \\
\hline & Left hemisphere - 37 \\
\hline & Right + Left hemisphere -3 \\
\hline & Brainstem - 16 \\
\hline & Cerebellum - 7 \\
\hline Manual preference (left/right/ambidextrous) & $3 / 82 / 1$ \\
\hline MMSE: illiterates ( $n=11)$ mean (SD) ; median (interval) & $19.4( \pm 1.55) ; 19(17-22)$ \\
\hline MMSE:1- 4 years of education ( $n=27)$ mean $(S D)$; median (interval) & $23.5( \pm 3.40) ; 25(20-30)$ \\
\hline MMSE: 5 - 8 years of education $(n=13)$ mean $(S D)$; median (interval) & 24.5 ( \pm 2.68$) ; 24(21-29)$ \\
\hline MMSE: over 8 years of education $(n=35)$ mean $(S D)$; median (interval) & $26.5( \pm 2.78) ; 28(20-30)$ \\
\hline Naming* mean (SD) ; median (interval) & $9.7( \pm 0.89) ; 10(3-10)$ \\
\hline Visual perception* mean (SD) ; median (interval) & $9.7( \pm 0.90) ; 10(3-10)$ \\
\hline Incidental memory* mean (SD) ; median (interval) & $5.4( \pm 1.46) ; 5(2-10)$ \\
\hline Immediate Memory 1* mean (SD) ; median (interval) & $7.5( \pm 1.52) ; 8(3-10)$ \\
\hline Immediate Memory 2* mean (SD) ; median (interval) & $8.2( \pm 1.58) ; 8(3-10)$ \\
\hline Delayed recall* mean (SD) ; median (interval) & $7.4( \pm 1.96) ; 8(0-10)$ \\
\hline Recognition* mean (SD) ; median (interval) & $9.5( \pm 1.05) ; 10(5-10)$ \\
\hline NIHSS mean (SD) ; median (interval) & $1.9( \pm 1.75) ; 1(0-6)$ \\
\hline Modified Rankin Scale mean (SD) ; median (interval) & $1.7( \pm 1.05) ; 2(0-4)$ \\
\hline Barthel Index mean (SD) ; median (interval) & $97.5( \pm 7.22) ; 100(40-100)$ \\
\hline Questionnaire (FAQ) mean (SD) ; median (interval) & $2.0( \pm 3.50) ; 26(11-27)$ \\
\hline
\end{tabular}

Table 2. Performance in the executive function scales and in the EFPT-BR.

\begin{tabular}{|c|c|}
\hline Executive function tests & Score $(n=86)$ means (SD); median (interval) \\
\hline $\begin{array}{l}\text { Semantic Verbal Fluency* } \\
0-1 \text { years of education, } n=11\end{array}$ & $9.1( \pm 3.7) ; 1(0-1)$ \\
\hline $\begin{array}{l}\text { Semantic Verbal Fluency* } \\
1-4 \text { years of education, } n=27\end{array}$ & $13.6( \pm 4.6) ; 4(1-4)$ \\
\hline $\begin{array}{l}\text { Semantic Verbal Fluency* } \\
5 \text { - } 8 \text { years of education, } n=13\end{array}$ & $13.4( \pm 4.2) ; 6(5-8)$ \\
\hline $\begin{array}{l}\text { Semantic Verbal Fluency* } \\
\text { Over } 8 \text { years of education, } n=35\end{array}$ & $15.2( \pm 5.2) ; 12(9-22)$ \\
\hline Clock Drawing Test* & $6.3( \pm 2.79) ; 7(2-10)$ \\
\hline Digit Span Forwards & $5.8( \pm 1.23) ; 6(2-7)$ \\
\hline Digit Span Backwards & $3.0( \pm 1.27) ; 3(0-6)$ \\
\hline $\begin{array}{l}\text { Stroop Test for illiterates (interference score, time in seconds) } \\
0-4 \text { years of education, } n=38\end{array}$ & $12.0( \pm 16.0) ; 7(-17-67)$ \\
\hline $\begin{array}{l}\text { Stroop Test for illiterates (interference score, time in seconds) } \\
\text { More than } 4 \text { years of education, } n=48\end{array}$ & $7.0( \pm 7.7) ; 6(-6-39)$ \\
\hline Zoo Map1 and 2 (BADS) & $2.2( \pm 0.73) ; 2(1-4)$ \\
\hline Modified six elements (BADS) & $2.4( \pm 0.94) ; 2(0-4)$ \\
\hline \multicolumn{2}{|l|}{ EFPT-BR } \\
\hline Simple meal preparation (median; intervals) & $1.0( \pm 1.8) ; 0(0-10)$ \\
\hline Phone call & $0.7( \pm 1.6) ; 0(0-9)$ \\
\hline Medication & $1.3( \pm 1.3) ; 1(0-7)$ \\
\hline Paying bills & $1.7( \pm 2.9) ; 3(0-10)$ \\
\hline EFPT total ccore & $5.9( \pm 5.2) ; 5(0-32)$ \\
\hline EFPT: total time in minutes & $17.1( \pm 5.5) ; 17(9.4-37.9)$ \\
\hline
\end{tabular}


Table 3. Internal consistency of the EFPT-BR.

\begin{tabular}{lc}
\hline EFPT-BR & $\begin{array}{c}\text { Correlation of the task with the } \\
\text { total score (Cronbach's alpha) }\end{array}$ \\
\hline Simple meal preparation & 0.564 \\
Phone call & 0.720 \\
Medication & 0.607 \\
\hline Paying bills & 0.704 \\
\hline EFPT-BR: Executive function performance test - Brazil.
\end{tabular}

There was significant correlation between the total score of the EFPT-BR and the following variables: age ( $\mathrm{rho}=0.290$, $\mathrm{p}=0.007$ ) and years of education ( rho $=-0.460, \mathrm{p}=0.000$ ). However, there was no significant correlation between the total score of the EFPT-BR and gender ( $r h o=-0.052, p=0.632)$, or for the Hospital Anxiety and Depression Scale ( $r h o=0.188$, $\mathrm{p}=0.091$ ), or for the Hamilton Depression Rating Scale's total score $(\mathrm{rho}=0.081, \mathrm{p}=0.452)$.

Table 4. Intra-rater and inter-rater reliability.

\begin{tabular}{|c|c|c|c|c|c|}
\hline \multirow{3}{*}{ EFPT-BR } & \multirow{3}{*}{$\begin{array}{c}\text { Total score in the } 1{ }^{\text {st }} \text { evaluation } \\
\text { (median and range) } \\
(n=30)\end{array}$} & \multirow{3}{*}{$\begin{array}{c}\text { Total score in the } 2^{\text {nd }} \text { evaluation } \\
\text { (median and range) } \\
(n=30)\end{array}$} & \multirow{3}{*}{ ICC } & \multirow{2}{*}{\multicolumn{2}{|c|}{ ICC (95\%) }} \\
\hline & & & & & \\
\hline & & & & Inferior & Superior \\
\hline Simple meal preparation & $0(0-2)$ & $0(0-2)$ & 0.000 & 0.000 & 0.362 \\
\hline Phone call & $0(0-3)$ & $0(0-2)$ & 0.190 & 0.000 & 0.515 \\
\hline Medication & $1(0-4)$ & $1(0-4)$ & 0.418 & 0.083 & 0.671 \\
\hline Paying bills & $3(0-5)$ & $2(0-5)$ & 0.317 & 0.000 & 0.603 \\
\hline Total score & $5(0-12)$ & $3(0-10)$ & 0.435 & 0.096 & 0.684 \\
\hline \multirow[t]{2}{*}{ EFPT-BR } & $\begin{array}{c}1^{\text {st }} \mathrm{OT} \\
\text { (median and range) }\end{array}$ & $\begin{array}{c}2^{\text {nd }} \mathrm{OT} \\
\text { (median and range) }\end{array}$ & ICC & \multicolumn{2}{|c|}{ ICC (95\%) } \\
\hline & $(n=40)$ & $(n=40)$ & & Inferior & Superior \\
\hline Simple meal preparation & $1(0-10)$ & $0(0-10)$ & 0.750 & 0.577 & 0.859 \\
\hline Phone call & $0(0-8)$ & $0(0-9)$ & 0.758 & 0.574 & 0.867 \\
\hline Medication & $1(0-5)$ & $1.5(0-7)$ & 0.393 & 0.109 & 0.621 \\
\hline Paying bills & $2.5(1-6)$ & $3(1-9)$ & 0.555 & 0.303 & 0.736 \\
\hline Total score & $6(1-25)$ & $7(1-29)$ & 0.732 & 0.516 & 0.855 \\
\hline
\end{tabular}

EFPT-BR: Executive Function Performance Test - Brazil; OT: occupational therapist; ICC: intra-class correlation (Cronbach's alpha)

Table 5. Correlations with the EFPT-BR

\begin{tabular}{|c|c|c|c|c|c|c|}
\hline Correlation (Spearman's rank) & & $\begin{array}{l}\text { Simple meal } \\
\text { preparation }\end{array}$ & Phone call & Medication & Paying bills & Total score \\
\hline \multirow{2}{*}{ Animal verbal fluency* } & rho & -0.243 & -0.358 & -0.333 & -0.365 & -0.452 \\
\hline & $\mathrm{p}$ & 0.024 & 0.001 & 0.002 & 0.001 & $<0.001$ \\
\hline \multirow{2}{*}{ Clock drawing test* } & rho & -0.214 & -0.184 & -0.271 & -0.237 & -0.324 \\
\hline & $p$ & 0.048 & 0.090 & 0.012 & 0.028 & 0.002 \\
\hline Digit span test & rho & -0.117 & -0.181 & -0.101 & -0.319 & -0.219 \\
\hline Foward & $p$ & 0.282 & 0.096 & 0.356 & 0.003 & 0.042 \\
\hline Digit span test & rho & -0.109 & -0.355 & -0.181 & -0.384 & -0.324 \\
\hline Backward & $p$ & 0.318 & 0.001 & 0.095 & $<0.001$ & 0.002 \\
\hline \multirow{2}{*}{ Stroop test (interference score) } & rho & -0.077 & 0.035 & 0.207 & 0.163 & 0.116 \\
\hline & $\mathrm{p}$ & 0.481 & 0.748 & 0.056 & 0.134 & 0.287 \\
\hline \multirow{2}{*}{ Zoo Map 1 and 2 BADS } & rho & -0.333 & -0.419 & -0.228 & -0.314 & -0.388 \\
\hline & $p$ & 0.002 & $<0.001$ & 0.035 & 0.003 & $<0.001$ \\
\hline Modified 6 elements & rho & -0.178 & -0.388 & -0.347 & -0.463 & -0.463 \\
\hline BADS & $p$ & 0.101 & $<0.001$ & 0.001 & $<0.001$ & $<0.001$ \\
\hline \multirow{2}{*}{ Barthel index } & rho & -0.197 & -0.119 & -0.331 & -0.135 & -0.263 \\
\hline & $p$ & 0.068 & 0.275 & 0.002 & 0.216 & 0.014 \\
\hline \multirow{2}{*}{$F A Q$} & rho & 0.380 & 0.219 & 0.303 & 0.295 & 0.420 \\
\hline & $\mathrm{p}$ & $<0.001$ & 0.042 & 0.005 & 0.006 & $<0.001$ \\
\hline \multirow{2}{*}{ IADL scale } & rho & -0.269 & -0.148 & -0.322 & -0.186 & -0.313 \\
\hline & $p$ & 0.012 & 0.175 & 0.002 & 0.086 & 0.003 \\
\hline
\end{tabular}

EFPT-BR: Executive function performance test-Brazil; * Brief cognitive screening battery; BADS: Behavioural assessment of the dysexecutive syndrome; FAQ: Functional activities questionnaire; IADL: Instrumental activities of daily living. 


\section{DISCUSSION}

In this study, we performed the cultural adaptation and evaluation of the psychometric properties of the EFPT-BR for Brazilian patients with stroke. The process of translation and cultural adaptation was necessary for the tasks to become more applicable to the everyday life in our country.

The majority of the sample comprised men (51/86), with mean age of 62 years and mean educational level of 7.4 years. In addition, this sample was similar to the samples from South Korea $\left(24 / 34\right.$ men) ${ }^{18}$ and Sweden $(16 / 23 \text { men })^{17}$, in which male participants predominated. On the other hand, in an American study ${ }^{12}$, there was a predominance of women. When compared with the education level, the sample had a lower educational level in our study, followed by the study in Sweden (9.5 years), South Korea (10.82 years) and United States (12 years). When observing the age range of the four studies, the Korean study had the youngest participants (54.4 years), followed by the Brazilian study (62 years), American (64 years), with the oldest participants, 72 years old, in Sweden. In the Swedish study ${ }^{17}$, the participants were considered independent according to the Barthel Index (60-100); as were those in the Korean study ${ }^{18}$ (Barthel Index, mean $=87.41$ ).

The result of the EFPT- BR showed that this is a reliable and valid instrument to assess the executive functions in the Brazilian population. Inter-rater reliability was intra-class correlation $(\mathrm{ICC})=0.732$, and was similar to other studies that used the EFPT in patients with stroke with results varying between ICC $=0.091$ and ICC $=0.087^{12,18}$. On the other hand, the intra-rater reliability did not show good results in this study. The meal preparation and phone call tasks showed very low ICC results, with a high prevalence of a zero score (20/30 for the meal preparation and 21/30 for the phone call), indicating that the participants were independent in these tasks. When there is a high prevalence of one category, the statistical tests will show a poor result, because you have a homogeneous sample ${ }^{39}$; however, the agreement between the two evaluations was high.

The EFPT-BR showed significant correlations with other executive function tests, except for the Stroop Test and the instrumental activities of daily living (Barthel Index, FAQ and IADL scale), reinforcing that the EFPT-BR is a valid tool for assessing executive functions. Significant correlations were shown by total scores, but also in subitems of the test; paying a bill had the highest correlation with other executive tasks, except for the Stroop Test. Participants had more difficulties in this task, because it was more complex, with different steps to follow to be completed. This may have been the reason why paying bills showed a better correlation with all the other executive function tools. Besides, in this task it was possible to assess the executive function in detail. The Korean study ${ }^{18}$ had similar results, where paying bills showed the best result; with the simple meal preparation being the second-best task.
The performance of the participants in the EFPT-BR was very good, compared with the original version ${ }^{12}$. The tasks with the best performance in the Brazilian version were the simple meal preparation and making a phone call. On the other hand, the tasks with the best performance in the original version were taking medication (mild stroke group) and paying the bills (moderate stroke group) ${ }^{12}$.

The meal preparation task showed significant correlation with only the following tests: Animal Verbal Fluency, Clock Drawing Test and the Zoo Map 1 and 2 of the Behavioral Assessment of the Dysexecutive Syndrome.

In the Korean study, however, the meal preparation task also showed a very good correlation with the other neuropsychology tools ${ }^{18}$. Both American and Korean meal preparation tasks are similar and more complex than preparing a cup of coffee. For a Brazilian, preparing coffee is probably a very common and simple task in their everyday routine, which explains why the score for this task was low, indicating a very good performance. It may explain the differences that occurred between the EFPT-BR and other versions in the literature.

The EFPT-BR also assesses (indirectly) the daily routine tasks. The correlations with the functional activities and the instrumental daily living activities were also significant, especially with the $\mathrm{FAQ}^{25}$. The questionnaire presented questions to patients and their family about independence in the instrumental activities of daily living. The questions are very similar to the tasks assessed directly by the EFPT-BR. The medication task was the only one that showed a correlation with the three functional scales (FAQ, IADL scale and Barthel Index).

The EFPT-BR also requires the ability to read and write to complete this scale and, thus, the adaptations for the participants who were illiterate were needed; moreover, there was a statistically significant correlation between the level of education and the EFPT-BR ( $\mathrm{p}=<0.001$ for the total score). Age was another factor that influenced the total score of the EFPT-BR, where older patients had a poor performance (rho $=0.290$ [0.007]).

This study had several limitations: the majority of the participants presented with mild stroke, with a Modified Rankin Scale score of 0 and $1(31 / 86,36 \%)$ and had a similar functional status, as the more severe patients were not able to come to the hospital without social and economic support. Moreover, the meal preparation task did not show a good result and had a ceiling effect. For future studies, we suggest another type of simple meal and a sample including patients with more severe stroke.

The results suggested that the EFPT-BR is a valid and reliable tool to assess the executive dysfunctions in patients with stroke in Brazil, in real-life routine tasks. The EFPT-BR is a valuable tool for OTs to assess executive functions in patients during the acute phase in hospital or in the chronic phase in a rehabilitation setting. 
1. World Health Organization. Stroke, cerebrovascular accident. Geneva: World Health Organization; 2014 [cited 2016 Aug 05]. Available from: http://www.who.int/topics/cerebrovascular_ accident/en/

2. Minelli C, Fen LF, Minelli DP. Stroke incidence, prognosis, 30-day, and 1-year case fatality rates in Matão, Brazil: a populationbased prospective study. Stroke. 2007 Nov;38(11):2906-11. https://doi.org/10.1161/STROKEAHA.107.484139

3. Cabral NL, Gonçalves AR, Longo AL, Moro CH, Costa G, Amaral CH et al. Trends in stroke incidence, mortality and case fatality rates in Joinville, Brazil: 1995-2006. J Neurol Neurosurg Psychiatry. 2009 Jul;80(7):749-54. https://doi.org/10.1136/jnnp.2008.164475

4. Cabral NL, Freire AT, Conforto AB, Santos N, Reis Fl, Nagel $\checkmark$ et al. Increase of stroke incidence in young adults in a middle-income country: a 10-year populationbased strudy. Stroke. 2017 Nov;48(11):2925-30. https://doi.org/10.1161/STROKEAHA.117.018531

5. Leśniak M, Bak T, Czepiel W, Seniów J, Członkowska A. Frequency and prognostic value of cognitive disorders in stroke patients. Dement Geriatr Cogn Disord. 2008;26(4):356-63. https://doi.org/10.1159/000162262

6. Barker-Collo S, Feigin VL, Parag V, Lawes CM, Senior H. Auckland Stroke Outcomes Study. Part 2: cognition and functional outcomes 5 years poststroke. Neurology. 2010 Nov;75(18):1608-16. https://doi.org/10.1212/WNL.0b013e3181fb44c8

7. Poulin V, Korner-Bitensky N, Dawson DR, Bherer L. Efficacy of executive function interventions after stroke: a systematic review. Top Stroke Rehabil. 2012 Mar-Apr;19(2):158-71. https://doi.org/10.1310/tsr1902-158

8. Brucki SM, Machado MF, Rocha MS. Vascular Cognitive Impairment (VCl) after non-embolic ischemic stroke during a 12-month follow-up in Brazil. Dement Neuropsychol. 2012 Jul-Sep;6(3):164-9. https://doi.org/10.1590/S1980-57642012DN06030009

9. Godofroy O, Stuss, D. Dysexecutive syndromes. In: Godefroy O, Bogousslavsky J, eds. The behavioral and cognitive neurology of stroke. Cambridge: University Press; 2007. p. 369-406.

10. Andrade SP, Brucki SM, Bueno OF, Siqueira Neto JI. Neuropsychological performance in patients with subcortical stroke. Arq Neuropsiquiatr. 2012 May;70(5):341-7. https://doi.org/10.1590/S0004-282X2012005000012

11. Zinn S, Bosworth HB, Hoenig HM, Swartzwelder HS. Executive function deficits in acute stroke. Arch Phys Med Rehabil. 2007 Feb;88(2):173-80. https://doi.org/10.1016/j.apmr.2006.11.015

12. Baum CM, Connor LT, Morrison T, Hahn M, Dromerick AW, Edwards DF. Reliability, validity, and clinical utility of the Executive Function Performance Test: a measure of executive function in a sample of people with stroke. Am J Occup Ther. 2008 Jul-Aug;62(4):446-55. https://doi.org/10.5014/ajot.62.4.446

13. Wolf TJ, Morrison T, Matheson L. Initial development of a workrelated assessment of dysexecutive syndrome: the Complex Task Performance Assessment. Work. 2008;31(2):221-8.

14. Josman N, Kizony R, Hof E, Goldenberg K, Weiss PL, Klinger $E$. Using the virtual action planning-supermarket for evaluating executive functions in people with stroke. J Stroke Cerebrovasc Dis. 2014 May-Jun;23(5):879-87. https://doi.org/10.1016/j.jstrokecerebrovasdis.2013.07.013

15. Motta K, Lee H, Falkmer T. Post-stroke driving: examining the effect of executive dysfunction. J Safety Res. 2014 Jun;49:33-8. https://doi.org/10.1016/j.jsr.2014.02.005

16. U.S. Department of Health and Human Services, Public Health Service, National Institutes of Health. Post-stroke rehabilitation. Bethesda: Natioal Institutes of Health; 2014. (NIH Publication, Vol. 141846).
17. Cederfeldt M, Widell Y, Andersson EE, Dahlin-Ivanoff S, Gosman-Hedström G. Concurrent validity of the Executive Function Performance Test in people with mild stroke. Br J Occup Ther. 2011;74(9):443-9. https://doi.org/10.4276/030802211X13153015305673

18. Kim H, Lee YN, Jo EM, Lee EY. Reliability and validity of culturally adapted executive function performance test for Koreans with stroke. J Stroke Cerebrovasc Dis. 2017 May;26(5):1033-40. https://doi.org/10.1016/j.jstrokecerebrovasdis.2016.12.013

19. Katz N, Tadmor I, Felzen B, Hartman-Maeir A. Validity of the Executive Function Performance Test in individuals with schizophrenia. OTJR. 2007;27(2):44-51. https://doi.org/10.1177/153944920702700202

20. Baum CM, Wolf TJ, Wong AW, Chen $\mathrm{CH}$, Walker K, Young AC et al. Validation and clinical utility of the executive function performance test in persons with traumatic brain injury. Neuropsychol Rehabil. $2017 \mathrm{Jul} ; 27(5): 603-17$. https://doi.org/10.1080/09602011.2016.1176934

21. Rankin J. Cerebral vascular accidents in patients over the age of 60. III. Diagnosis and treatment. Scott Med J. 1957 Jun;2(6):254-68. https://doi.org/10.1177/003693305700200604

22. Caneda MAG, Fernandes JG, Almeida AG, Mugnol FE. [Reliability of neurological assessment scales in patients with stroke]. Arq Neuropsiquiatr. 2006 Sept;64(3):690-7. Portuguese. https://doi.org/10.1590/S0004-282X2006000400034

23. Oldfield RC. The assessment and analysis of handedness: the Edinburgh inventory. Neuropsychologia. 1971 Mar;9(1):97-113. https://doi.org/10.1016/0028-3932(71)90067-4

24. Paixão Junior CM, Reichenheim ME. [A review of functional status evaluation instruments in the elderly]. Cad Saúde Pública. 2005; 21(1):7-19. Portuguese. https://doi.org/10.1590/S0102-311X2005000100002

25. Pfeffer RI, Kurosaki TT, Harrah CH Jr, Chance JM, Filos S. Measurement of functional activities in older adults in the community. J Gerontol. 1982 May;37(3):323-9. https://doi.org/10.1093/geronj/37.3.323

26. Lawton MP, Brody EM. Assessment of older people: self-maintaining and instrumental activities of daily living. Gerontologist. 1969;9 (3):179-86.

27. Carod-Artal FJ, Coral LF, Trizotto DS, Moreira CM. The stroke impact scale 3.0: evaluation of acceptability, reliability, and validity of the Brazilian version. Stroke. 2008 Sep;39(9):2477-84. https://doi.org/10.1161/STROKEAHA.107.513671

28. Folstein MF, Folstein SE, McHugh PR. "Mini-mental state": a practical method for grading the cognitive state of patients for the clinician. J Psychiatr Res. 1975 Nov;12(3):189-98. https://doi.org/10.1016/0022-3956(75)90026-6

29. Brucki SM, Nitrini R, Caramelli P, Bertolucci PH, Okamoto IH. [Suggestions for utilization of the mini-mental state examination in Brazil]. Arq Neuropsiquiatr. 2003 Sep;61(3B):777-81. Portuguese. https://doi.org/10.1590/S0004-282X2003000500014

30. Nitrini R, Brucki SM, Smid J, Carthery-Goulart MT, Renato A, Areza-Fegyveres R et al. Influence of age, gender and educational level on performance in the Brief Cognitive Battery-Edu. Dement Neuropsychol. 2008 Apr-Jun;2(2):114-8. https://doi.org/10.1590/S1980-57642009DN20200007

31. Wechsler D. Bellevue intelligence scale. New York: The Psychological Corporation; 1939.

32. Cunha JA. As escalas Wechsler. In: Cunha JÁ, ORG. Psicodiagnóstico-R. Porto Alegre: Artes Médicas; 1993. p. 278-354.

33. Kulaif T, Valle LE. Alternative to the Stroop Color-Word Test for illiterate individuals. Clin Neuropsychol. 2008 Jan;22(1):73-83. https://doi.org/10.1080/13854040601186964 
34. Armentano, CGC; Porto, CS; Brucki, SMD; Nitrini, R. Study on the Behavioural Assessment of the Dysexecutive Syndrome (BADS) performance in healthy individuals, mild Cognitive impairment and Alzheimer's disease: a preliminary study. Dementia \& Neuropsychologia; v.3n.2p101-107.

35. Zigmond AS, Snaith RP. The hospital anxiety and depression scale. Acta Psychiatr Scand. 1983 Jun;67(6):361-70. https://doi.org/10.1111/j.1600-0447.1983.tb09716.x

36. Furukawa TA, Akechi T, Azuma H, Okuyama T, Higuchi T. Evidencebased guidelines for interpretation of the Hamilton Rating Scale for Depression. J Clin Psychopharmacol. 2007 Oct;27(5):531-4. https://doi.org/10.1097/JCP.0b013e31814f30b1.
37. Guillemin F, Bombardier C, Beaton D.

Cross-cultural adaptation of health-related quality of life measures: literature review and proposed guidelines. J Clin Epidemiol. 1993 Dec;46(12):1417-32. https://doi.org/10.1016/0895-4356(93)90142-N

38. Beaton DE, Bombardier C, Guillemin F, Ferraz MB. Guidelines for the process of cross-cultural adaptation of self-report measures. Spine. 2000 Dec;25(24):3186-91. https://doi.org/10.1097/00007632-200012150-00014

39. Sainani KL. Reliability statistics. PM\&R. 2017 Jun;9(6):622-8. https://doi.org/10.1016/j.pmrj.2017.05.001 